\title{
SWEDISH RED CROSS CONFERENCE
}

Twenty-two district secretaries who have key roles in the regional management of the Swedish Red Cross held their annual conference in Geneva at the Henry Dunant Institute from 3 to 7 February 1975. The conference consisted in a seminar programme organized by eight officers of the Society's national headquarters, with the co-operation of members of the International Red Cross institutions.

The participants studied the structure, aims and activities of the International Red Cross in order to develop their skills in providing information and helping the public to understand the principles of the Red Cross and its work. They also examined the practical problems involved in providing protection and assistance to victims of man-made and natural disasters. The Red Cross development programme was also the subject of a series of group exercises.

Special attention was devoted to the improvement of communications between the National Society and the International Red Cross institutions in Geneva.

\section{HENRY DUNANT INSTITUTE 1}

It will be recalled that International Review published in its August 1974 issue an article on Henry Dunant which had been written by Pierre Boissier only a short time before his death. The Henry Dunant Institute, of which Pierre Boissier was director, has now issued this study in a 24page booklet available from the Institute in four languages: English, French, German and Spanish.

A year has now gone by since the Institute was set up in its new premises. The move was made possible through the generosity of the City of Geneva and the Swiss Confederation. The building now housing the Institute contains offices, large assembly rooms, a library and a museum which is open to the public and where documents and other items relating to Dunant and to Red Cross work throughout the world are displayed.

${ }^{1}$ Address: Institut Henry-Dunant, 114 rue de Lausanne, 1202 Geneva. Price of booklet: Sw.fr. 2.00 . 